\title{
Article \\ Synthesis of New Water Soluble $\beta$-Cyclodextrin@Curcumin Conjugates and In Vitro Safety Evaluation in Primary Cultures of Rat Cortical Neurons
}

\author{
Amina Ben Mihoub ${ }^{1,2,3, *}$, Samir Acherar ${ }^{2, *} \mathbb{D}$, Céline Frochot ${ }^{3}\left(\mathbb{D}\right.$, Catherine Malaplate ${ }^{4}$, Frances T. Yen ${ }^{4}$ (D) and \\ Elmira Arab-Tehrany ${ }^{1, *}$
}

1 LIBio Laboratory, Université de Lorraine, F-54000 Nancy, France

2 LCPM, CNRS, Université de Lorraine, F-54000 Nancy, France

3 LRGP, CNRS, Université de Lorraine, F-54000 Nancy, France; celine.frochot@univ-lorraine.fr

4 URAFPA, INRAE, Université de Lorraine, F-54000 Nancy, France; catherine.malaplate-armand@univ-lorraine.fr (C.M.); frances.yen-potin@univ-lorraine.fr (F.T.Y.)

* Correspondence: amina.ben-mihoub@univ-lorraine.fr (A.B.M.); samir.acherar@univ-lorraine.fr (S.A.); elmira.arab-tehrany@univ-lorraine.fr (E.A.-T.)

check for updates

Citation: Ben Mihoub, A.; Acherar, S.; Frochot, C.; Malaplate, C.; Yen, F.T.; Arab-Tehrany, E. Synthesis of New Water Soluble $\beta$-Cyclodextrin@ Curcumin Conjugates and In Vitro Safety Evaluation in Primary Cultures of Rat Cortical Neurons. Int. J. Mol. Sci. 2021, 22, 3255. https://doi.org/ $10.3390 /$ ijms 22063255

Academic Editor: Stephen C. Bondy

Received: 18 February 2021

Accepted: 19 March 2021

Published: 23 March 2021

Publisher's Note: MDPI stays neutral with regard to jurisdictional claims in published maps and institutional affiliations.

Copyright: (c) 2021 by the authors. Licensee MDPI, Basel, Switzerland. This article is an open access article distributed under the terms and conditions of the Creative Commons Attribution (CC BY) license (https:// creativecommons.org/licenses/by/ $4.0 /)$.
Abstract: Self-aggregation of Curcumin (Cur) in aqueous biological environment decreases its bioavailability and in vivo therapeutic efficacy, which hampers its clinical use as candidate for reducing risk of neurodegenerative diseases. Here, we focused on the design of new Cur- $\beta$-Cyclodextrin nanoconjugates to improve the solubility and reduce cell toxicity of Cur. In this study, we described the synthesis, structural characterization, photophysical properties and neuron cell toxicity of two new water soluble $\beta-\mathrm{CD} / \mathrm{Cur}$ nanoconjugates as new strategy for reducing risks of neurodegenerative diseases. Cur was coupled to one or two $\beta$-CD molecules via triazole rings using CuAAC click chemistry strategy to yield $\beta$-CD@Cur and $(\beta-C D)_{2} @ C$ ur nanoconjugates, respectively. The synthesized nanoconjugates were found to be able to self-assemble in aqueous condition and form nano-aggregates of an average diameter size of around 35 and $120 \mathrm{~nm}$ for $\beta$-CD@Cur and $(\beta-C D)_{2} @ C u r$ respectively. The photophysical properties, water solubility and cell toxicity on rat embryonic cortical neurons of the designed nanoconjugates were investigated and compared to that of Cur alone. The findings revealed that both new nanoconjugates displayed better water solubility and in vitro biocompatibility than Cur alone, thus making it possible to envisage their use as future nano-systems for the prevention or risk reduction of neurodegenerative diseases.

Keywords: curcumin; $\beta$-cyclodextrin; click chemistry; nanoconjugates; neurodegenerative prevention

\section{Introduction}

Neurodegenerative diseases, such as Parkinson's and Alzheimer's diseases, as well as spinocerebellar ataxias, are common causes of cognitive impairment and morbidity in older adults [1,2]. The heterogeneous clinical presentation and physiopathology of the neural disorders that characterize these diseases can also be associated with inflammation, oxidative damage and the protein aggregate formation [3,4]. Epidemiological studies point towards natural antioxidant agents as promising therapeutic agents to prevent or delay the occurrence of neurodegenerative diseases [5].

Curcumin (Cur) is the major polyphenolic compound of Curcuma longa, an herbaceous plant endemic to South Asia [6]. There have been numerous studies on the bioactivity and health benefits of Cur, including its antioxidant, anti-inflammatory, antitumor and neuroprotective effects [7]. In recent years, this drug has been considered as a potential treatment for multiple neurodegenerative disorders [8]. Moreover, multiple studies in rodents and humans have shown that Cur crosses the blood-brain barrier (BBB) [5]. However, despite its many biological activities, Cur is not often used in clinical applications 
because of two main intrinsic properties: Low bioavailability due to its limited solubility in water $(11 \mathrm{ng} / \mathrm{mL})$ and low permeability (LogP 3.28) [9].

Recently, Cur-based nano-systems, including liposomes, polymeric nanoparticles, micelles, conjugates, solid dispersion, emulsion, peptide carriers and cyclodextrins (CDs) have been proposed as suitable and promising systems for enhancing the overall bioavailability, biodistribution and controlled release of Cur, along with reducing Cur toxic effects, and increased transport across the BBB [4,7,9-12]. Because of their unique physicochemical and structural properties, $\mathrm{CDs}$ were considered as one of the most promising biocompatible nanovectors for Alzheimer's disease (AD) $[13,14]$. CDs $(\alpha-, \beta-$, and $\delta-C D)$ are a family of natural glucopyranose-based cyclic oligosaccharides, with hydrophobic internal and hydrophilic external surfaces by the exposure of hydroxyl units [10]. CDs and their derivatives proved to form complexes with Cur [15-21], improving its water solubility by around 100 times, its bioactivity [15-18] and its anti-AD therapeutic effect [19-21]. To our knowledge, the improvement of Cur water solubility and anti-AD therapeutic efficacy with CDs has been investigated, but only in cases of complex formation through non-covalent binding.

In this current study, we explored two new nanoconjugates based on the covalent binding of Cur to either one or two $\beta$-CD molecules identified as $\beta$-CD@Cur and $(\beta-C D)_{2} @ C u r$, respectively (Figure 1). The two nanoconjugates were synthesized using Copper-Catalyzed Azide-Alkyne Cycloaddition (CuAAC) click chemistry. They were characterized by DLS, NMR $\left({ }^{1} \mathrm{H},{ }^{13} \mathrm{C}, \mathrm{HMBC}\right.$ and HSQC), HRMS and HPLC techniques. The effect of the covalent binding on Cur disaggregation in aqueous conditions was investigated by spectroscopic measurements. Finally, cytotoxic studies were performed on primary cultures of rat embryonic cortical neurons to evaluate the behavior of the nanoconjugates in a biological environment.
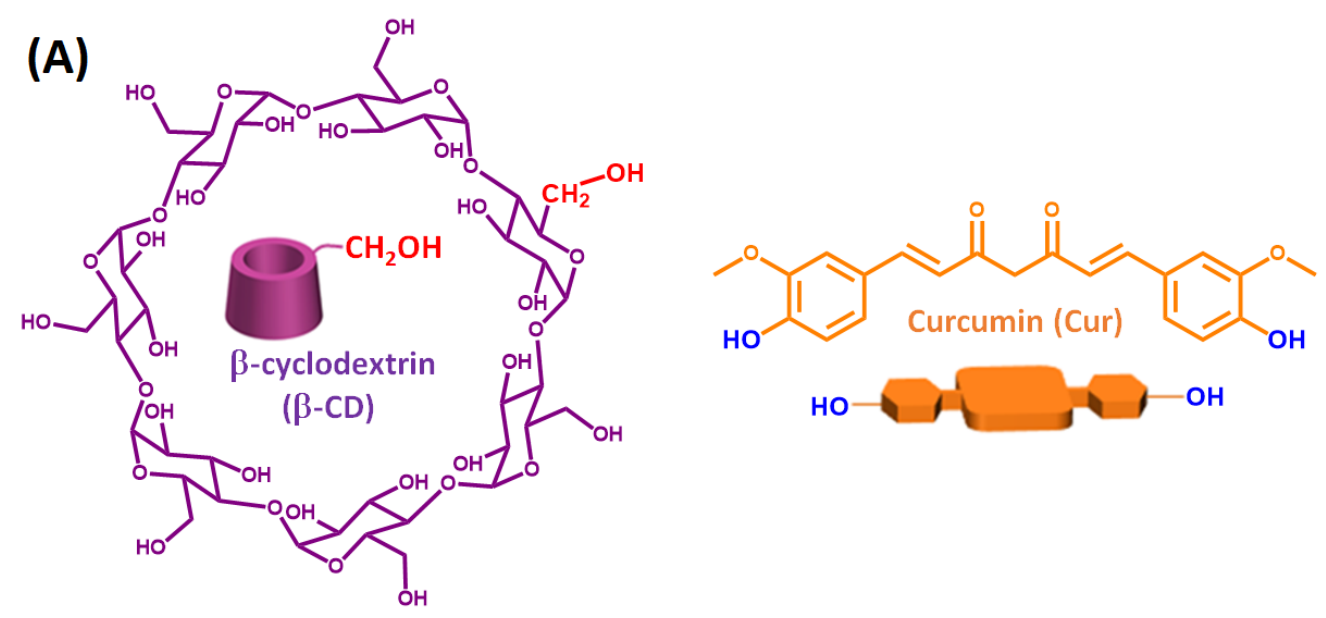

(B)

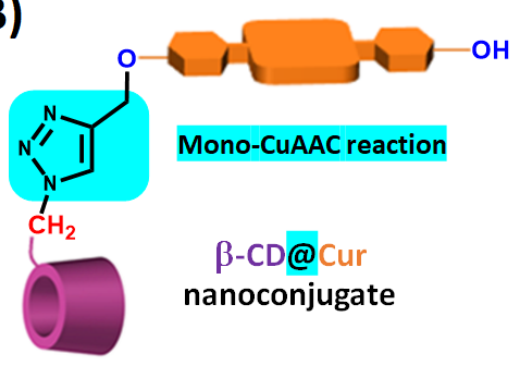

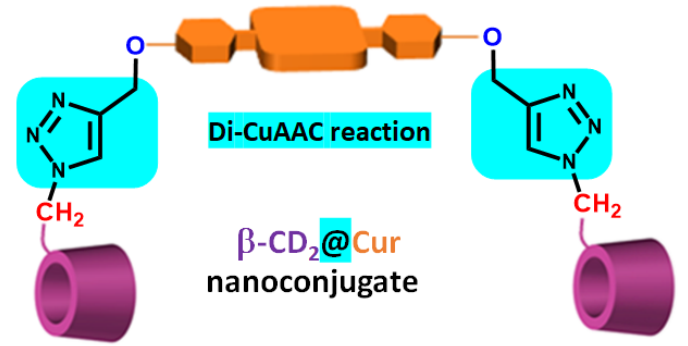

Figure 1. (A) Chemical structures of $\beta-C D$ and $C u r$, and (B) schematic illustration of $\beta-C D @ C$ ur and $(\beta-C D)_{2} @ C$ ur nanoconjugates obtained through mono- and di-CuAAC reaction. 


\section{Results and Discussion}

\subsection{Synthesis of $\beta$-CD@Cur 4 and $(\beta-C D)_{2} @ C$ ur 5 Nanoconjugates}

For the synthesis of the nanoconjugates $\beta$-CD@Cur 4 and $(\beta-C D)_{2} @ C u r 5$, Cur was combined with $\beta$-CD via a triazole covalent linkage using a CuAAC click chemistry strategy. To achieve this goal, Cur mono-alkyne 1, Cur di-alkyne 2 and mono-6-azido- $\beta$-CD 3 were first synthesized as previously described [22,23] (Scheme 1).

(A)
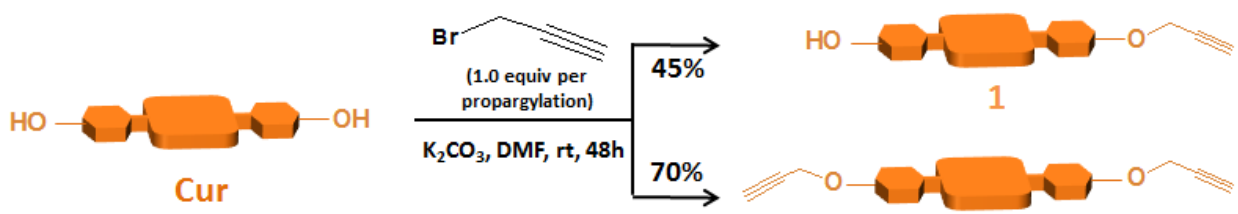

2

(B)
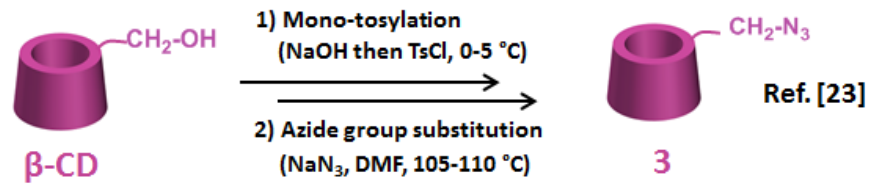

$49 \%$

(C)
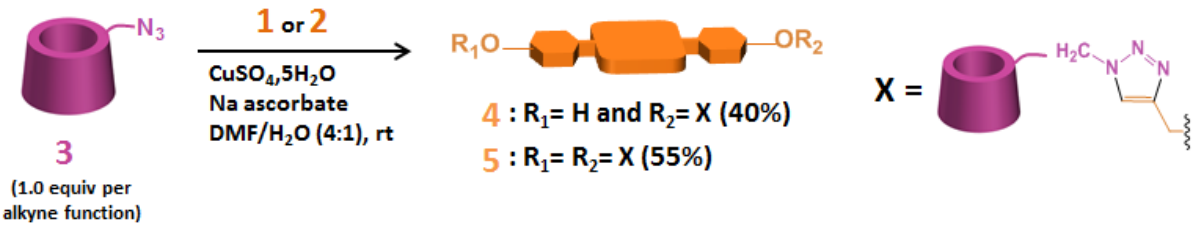

Scheme 1. Synthesis of (A) Cur mono-alkyne 1 and Cur di-alkyne 2, (B) mono-6-azido- $\beta$-CD 3, and (C) $\beta$-CD@Cur 4 and $(\beta-C D)_{2} @ C u r 5$ nanoconjugates.

The obtained yields of Cur mono-alkyne 1 and Cur di-alkyne 2 were relatively good (45\% and 70\%, respectively). These compounds were synthesized separately by mono- and di-etherification of Cur with propargyl bromide (1.0 equiv. per propargylation) in alkaline conditions using a previous protocol described by Raja et al. [22] with slight modifications (Scheme 1A). Compounds 1 and $\mathbf{2}$ were characterized by HPLC, ${ }^{1} \mathrm{H}$ NMR and HRMS (see supplementary data).

Mono-6-azido- $\beta$-CD 3 was prepared in two steps from $\beta$-CD according to the protocol previously described by our team [23] with a $49 \%$ overall yield (Scheme 1B). These two steps consisted of mono-tosylation of $\beta-\mathrm{CD}$ on the primary OH- 6 function, followed by its nucleophilic substitution by an azide group.

$\beta-C D @ C u r 4$ and $(\beta-C D)_{2} @ C u r 5$ resulting from single and double "click" conjugations between alkyne-modified Cur ( $\mathbf{1}$ or 2 ) and azide-functionalized $\beta$-CD 3 were obtained as an orange powder and as a yellowish powder with $40 \%$ and $55 \%$ yields, respectively (Scheme 1C).

The purity of the obtained nanoconjugates was determined by analytical HPLC and NMR analysis. The HPLC purity of both nanoconjugates was determined using reverse phase and based on the UV-visible detection ( 254 and $420 \mathrm{~nm}$ ). As shown in Figure 2, both $\beta$-CD@Cur 4 and $(\beta-C D)_{2} @ C$ Cur 5 nanoconjugates showed an excellent purity $(94.2 \%$ and $95.3 \%$ for 4 and 5 , respectively). 


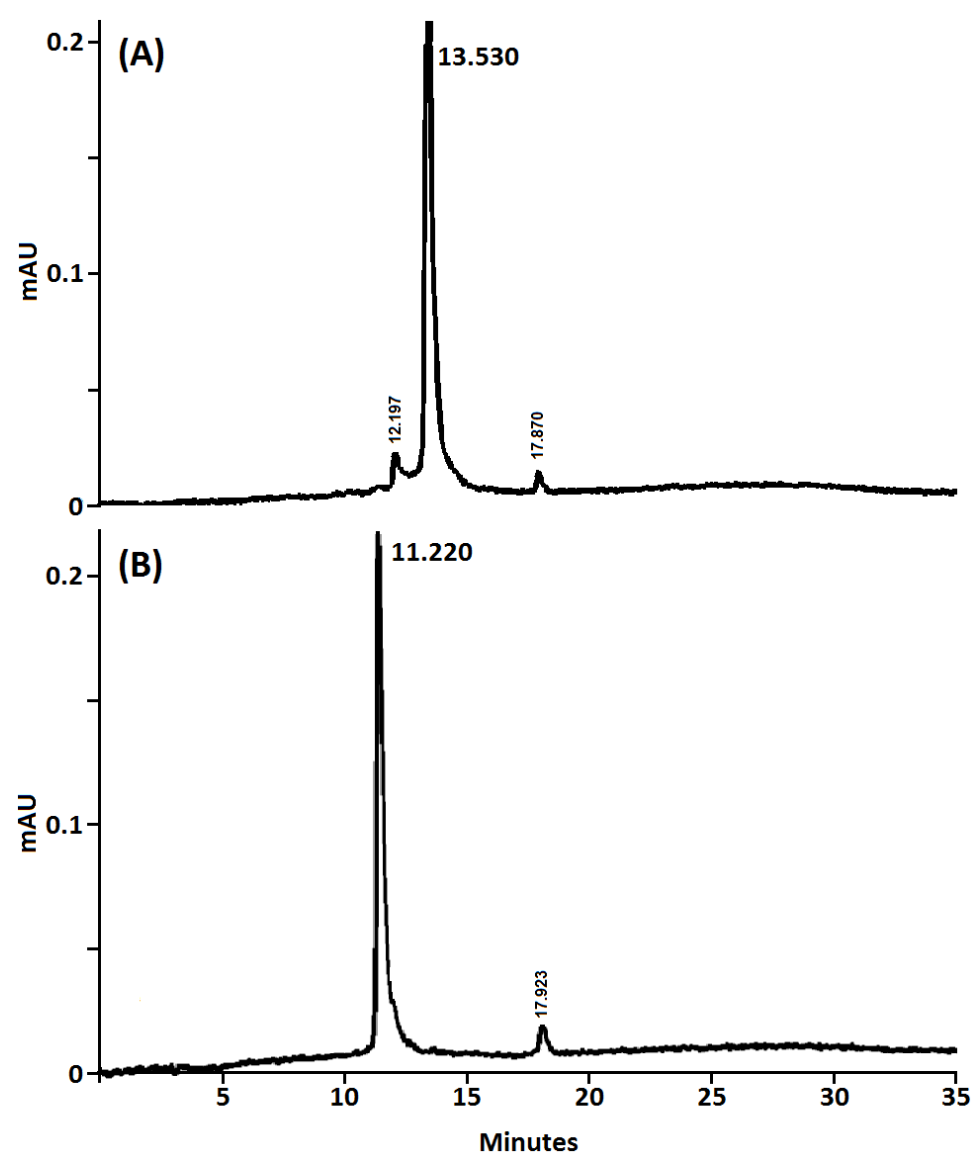

Figure 2. Analytical HPLC chromatograms (UV detection at $420 \mathrm{~nm}$ ) of (A) $\beta$-CD@Cur 4 and (B) ( $\beta$ $\mathrm{CD})_{2} @$ Cur 5 nanoconjugates (C18 column, ACN $/ \mathrm{H}_{2} \mathrm{O}$ containing $0.1 \%$ TFA, v/v gradients from 10/90 to $100 / 0$ in $25 \mathrm{~min}$, then $100 / 0$ for $10 \mathrm{~min}$ ).

The purity and the successful synthesis of both nanoconjugates were characterized with $1 \mathrm{D}$ and 2D NMR $\left({ }^{1} \mathrm{H},{ }^{13} \mathrm{C}, \mathrm{HSQC}\right.$ and HMBC) and HRMS analyses. All 1D and 2D NMR spectra of nanoconjugates $\mathbf{4}$ and $\mathbf{5}$ are included in supplemental data (Figures S1-S8). In the ${ }^{1} \mathrm{H}$ NMR spectra of $\beta$-CD@Cur 4 and $(\beta-C D)_{2} @ C$ ur 5 (Figures S1 and S5), the characterization was based on the complete clearance of the propargylic $\mathrm{CH}$ signal at $3.59 \mathrm{ppm}$ and the appearance of the characteristic signal of the triazole ring at around $8.20 \mathrm{ppm}$. The obtention of the mono-CuAAC reaction was also evidenced in NMR spectra of $\beta$-CD@Cur 4 by the presence of (i) one hydroxyl group at $9.67 \mathrm{ppm}$ in the ${ }^{1} \mathrm{H}$ NMR spectrum (i.e., one phenol group in Cur unit, Figure S1) and (ii) duplicated signals in the ${ }^{1} \mathrm{H}$ and ${ }^{13} \mathrm{C}$ NMR spectra (i.e., $\mathrm{H}_{3} / \mathrm{H}_{3^{\prime}}, \mathrm{H}_{4} / \mathrm{H}_{4^{\prime}}, \mathrm{H}_{6} / \mathrm{H}_{6^{\prime}}, \mathrm{H}_{9} / \mathrm{H}_{9^{\prime}}$ and $\mathrm{H}_{10} / \mathrm{H}_{10^{\prime}}$ in the ${ }^{1} \mathrm{H}$ NMR spectrum, Figure $\mathrm{S} 1$, and $\mathrm{C}_{2}-\mathrm{C}_{\mathbf{1 0}} / \mathrm{C}_{\mathbf{2}^{\prime}}-\mathrm{C}_{10^{\prime}}$ in the ${ }^{13} \mathrm{C}$ NMR spectrum, Figure S2) due to the presence of dissymmetry in $\beta$-CD@Cur 4. Compared to $\beta$-CD@Cur 4, in the ${ }^{1} \mathrm{H}$ and ${ }^{13} \mathrm{C}$ NMR spectra of $(\beta-\mathrm{CD})_{2} @ \mathrm{Cur} 5$ (Figures S5 and S6), the di-CuAAC reaction was evidenced by the disappearance of (i) the ${ }^{1} \mathrm{H}$ NMR signal of the hydroxyl group (i.e., no phenol group in Cur unit, Figure S5) and (ii) the duplication of signals in ${ }^{1} \mathrm{H}$ and ${ }^{13} \mathrm{C}$ NMR spectra (Figures S5 and S6). Finally, the ${ }^{1} \mathrm{H}$ and ${ }^{13} \mathrm{C}$ NMR signals of 4 and 5 were fully assigned using 2D NMR experiments (Figures S3, S4, S6 and S8).

\subsection{Size and Morphological}

To investigate the size and morphology of the developed $\beta$-CD@Cur 4 and ( $\beta$ $\mathrm{CD})_{2} @$ Cur 5 nanoconjugates, DLS and TEM analyses were performed. As shown in Figure 3, the synthesized supramolecular nanoconjugates displayed a tendency to selfassemble in water due to the strong interaction between Cur and $\beta-\mathrm{CD}(\mathrm{O}-\mathrm{H}$ bonds, 
Host-Guest, etc.). The self-assembled $\beta-C D @ C u r 4$ had an average hydrodynamic diameter of $35.2 \pm 2.1 \mathrm{~nm}$ in the DLS profile and zeta potential of $-28.5 \pm 1.2 \mathrm{mV}$ (Figure 3A). The self-assembled $(\beta-C D)_{2} @ C$ ur 5 showed a larger mean diameter of $120.3 \pm 1.1 \mathrm{~nm}$ and zeta potential of $-25.7 \pm 0.7 \mathrm{mV}$ (Figure 3B). This increase in the mean diameter may be accounted by the presence of the double amount of $\beta-C D$ in nanoconjugate 5 compared to 4 .
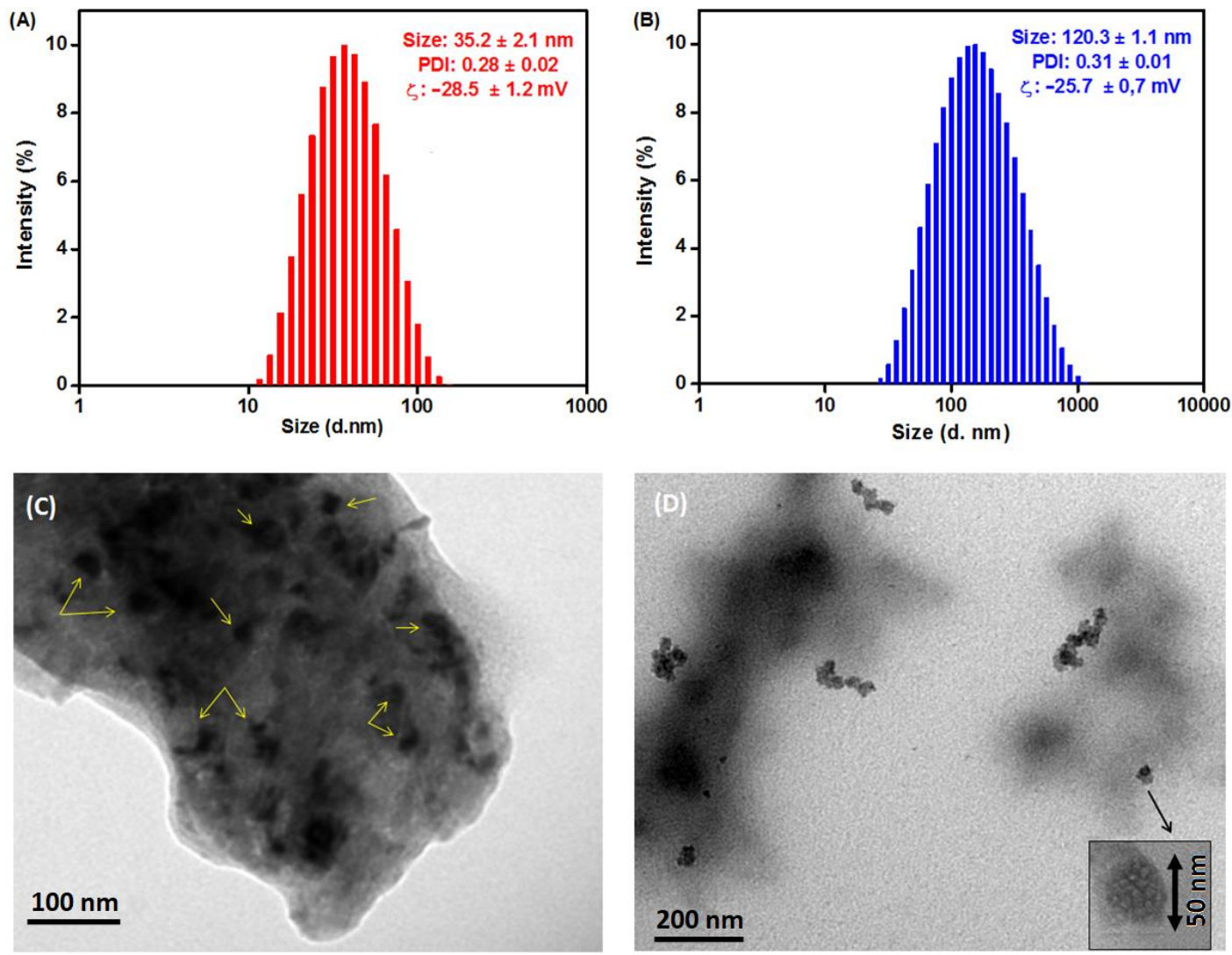

Figure 3. DLS profiles in water of (A) $\beta$-CD@Cur 4 and (B) $(\beta-C D)_{2} @$ Cur 5. TEM images of $(\mathbf{C}) \beta-C D @ C u r 4$ and (D) $(\beta-C D)_{2} @$ Cur 5.

As depicted in TEM images (Figure 3C,D), $\beta$-CD@Cur 4 and $(\beta-C D)_{2} @ C$ ur 5 showed spherical morphology with an average size of around $25 \mathrm{~nm}$ for $\beta$-CD@Cur 4 (Figure 3C) and $50 \mathrm{~nm}$ spheres aggregated into chains of diameter size around $100 \mathrm{~nm}(\beta-C D)_{2} @ C u r 5$ (Figure 3D). The size differences obtained by both DLS and TEM are possible, since DLS and TEM are two different techniques. Indeed, DLS provides the hydrodynamic diameter of swollen vesicles in solution [24]. TEM allows to obtain two-dimensional image of the dried form [25]. This size difference could be also linked to the fact that we obtain relatively high PDI values of around 0.3 for both nanoconjugates resulting in a wide distribution of sizes and different size visualization in TEM images.

\section{3. $\beta-C D$ Effect on the Cur Disaggregation in Aqueous Medium}

Cur is a natural hydrophobic photosensitizer having a low water solubility (i.e., $11 \mathrm{ng} / \mathrm{mL}$ [9]). Generally, hydrophobic photosensitizers have the tendency to self-aggregate in aqueous media due to their conjugated $\pi-\pi$ electronic structure resulting in the obtention of broad UV-vis absorption peaks with low intensity and quenching fluorescence emission. In the case of Cur, experimental study on the Cur aggregation revealed that its aggregation in water is due to $\pi$-stacking of phenyl rings and H-bonds with side groups [26], leading to a red Stockes shift by comparing UV-vis absorption and fluorescence emission spectra [27]. It is worth noting that $\beta-C D$ is a natural cyclic oligosaccharide consisting of 
$\alpha-1,4$-glucopyranose units. In contrast with curcumin, $\beta$-CD does not have a conjugated $\pi-\pi$ electronic structure, with the result that $\beta-C D$ does not absorb and fluoresce in the UV-vis. $\beta-C D$ is biocompatible and biodegradable oligosaccharide known to improve the solubility, stability and bioavailability of drugs.

The effect of $\beta-C D$ on the disaggregation of Cur in aqueous medium was investigated by comparing the photophysical properties of nanoconjugates 4 and 5 to those of the free Cur in water. The UV-vis absorption, fluorescence emission and fluorescence lifetime spectra in water of the studied molecules are shown in Figure 4. As shown in Figure 4A, in aqueous conditions (neutral water), Cur exhibited a broad absorption band at around $427 \mathrm{~nm}$ with a shoulder at $\sim 350 \mathrm{~nm}$, which arise assigned to the $\pi-\pi^{*}$ transitions associated with the conjugated Cur and the feruloyl unit, respectively $[28,29]$.
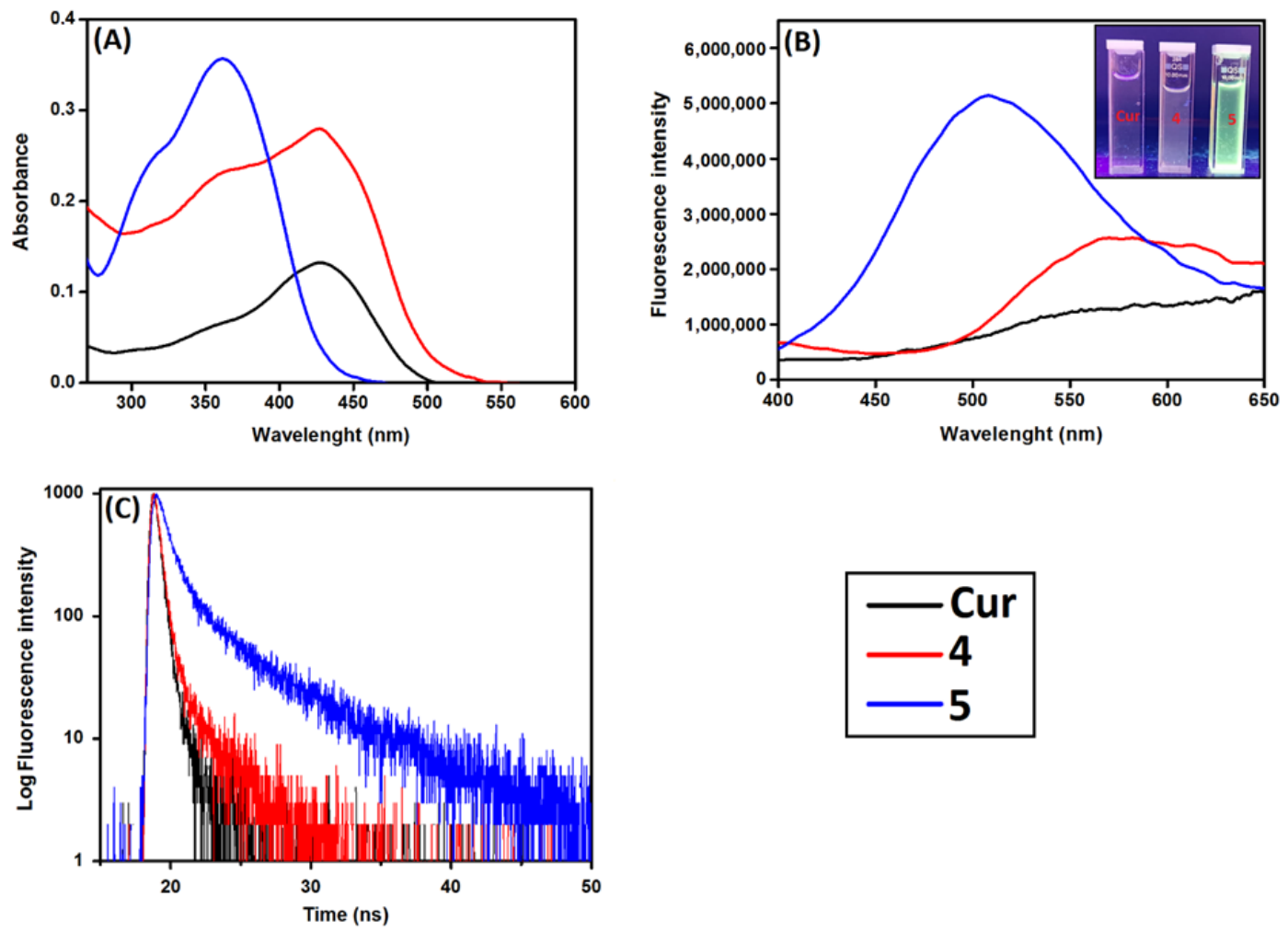

Figure 4. Photophysical properties of Cur, $\beta$-CD@Cur 4 and $(\beta-C D)_{2} @ C$ ur 5 in $\mathrm{D}_{2} \mathrm{O}$ at room temperature. (A) UV-vis absorption spectra at a single concentration of Cur $(c=12 \mu \mathrm{M})$, and (B) fluorescence emission and (C) fluorescence lifetime spectra at $\lambda_{\mathrm{exc}}=360 \mathrm{~nm}\left(\mathrm{~A}_{360 \mathrm{~nm}}=0.2\right)$.

By covalent binding of Cur to $\beta$-CD molecules, two important changes in the UVvis absorption spectra of Cur were observed. First, a hyperchromic effect was observed in the UV-vis spectra of both nanoconjugates in $\mathrm{D}_{2} \mathrm{O}$, where the absorption intensity of Cur in water increased significantly depending on the number of $\beta-C D$ molecules coupled to Cur (Figure 4A), indicating an increase in the solubilization of Cur inside the nanoconjugates [28-30]. Second, the broad absorption band at $427 \mathrm{~nm}$ became narrower in the case of both nanoconjugates and a significant blue shift to $365 \mathrm{~nm}$ occurred in the case of the nanoconjugate 5 (Figure 4A). Such changes might be due to the Cur $\pi$-electrons interaction with the hybridized orbitals of the surface oxygen atoms of $\beta-C D$, leading to destabilization of the $\pi^{*}$-orbitals, and a stabilization of the $\pi$-orbitals causing a blue shift of the absorption band of the coupled Cur [29].

The effect of $\beta$-CD on the fluorescence intensity and lifetime of Cur in $\mathrm{D}_{2} \mathrm{O}$ was also investigated. As shown in Figure 4B, Cur had a tendency to quench in aqueous media leading to weak fluorescence intensity with a broad emission spectrum centered at $550 \mathrm{~nm}$ and fluorescence lifetime of $1.6 \mathrm{~ns}$ (Figure $4 \mathrm{C}$, Table 1). However, by coupling Cur to $\beta-\mathrm{CD}$, 
a significant enhancement of fluorescence intensity occurred depending on the number of $\beta$-CD coupled to Cur with an important blue-shift in the emission maxima in the case of nanoconjugate 5 (Figure 4B). This effect could be visually observed under a UV light of $365 \mathrm{~nm}$ (top right of Figure 4B). Moreover, fluorescence quantum yield and fluorescence lifetime increased by increasing covalent binding of Cur to $\beta-C D$ (Figure $4 C$, Table 1 ). This might be due to a decrease of the aggregation and the presence of the nanoconjugates monomers in water. Such results demonstrated that: (i) Covalent binding of Cur to $\beta-C D$ decreased its self-aggregation in aqueous conditions and (ii) the disaggregation phenomenon was highly dependent on the number of $\beta-C D$ units linked to Cur (i.e., the more there are, the better).

Table 1. Photophysical properties of Cur and nanoconjugates 4 and 5.

\begin{tabular}{ccccc}
\hline Compounds & $\boldsymbol{\lambda}_{\text {abs, } \max }(\mathbf{n m})$ & $\boldsymbol{\lambda}_{\mathrm{em}, \max }(\mathbf{n m})$ & $\boldsymbol{\phi}_{\mathbf{f}}$ & $\tau(\mathbf{n s})$ \\
\hline Cur & 428 & $\sim 580$ & $<<0.01$ & 1.6 \\
$\beta-C D @ C u r$ 4 & 426 & 580 & 0.03 & 2.8 \\
$(\beta-C D)_{2} @$ Cur 5 & 365 & 507 & 0.09 & 6.4 \\
\hline
\end{tabular}

\subsection{Treatment of Primary Cultured Neurons with Nanoconjugates $\mathbf{4}$ and $\mathbf{5}$}

The cytotoxic effect of the synthesized nanoconjugates $\mathbf{4}$ and $\mathbf{5}$ on primary cultures of rat embryo cortical neurons was investigated (the day of cell isolation and preparation of culture was Day $0(\mathrm{D} 0))$. To assess cytotoxic effects of $\beta$-CD@Cur 4 and $(\beta-C D)_{2} @$ Cur 5 nanoconjugates, primary cultures of neurons were prepared followed by $24 \mathrm{~h}$ incubation starting on D3 in the absence or presence of the nanoconjugates at Cur concentrations of 2, $5,10,15$ and $20 \mu \mathrm{M}$. Cell viability (Figure 5 ) was determined by the MTT assay on D4 as previously described [31,32].

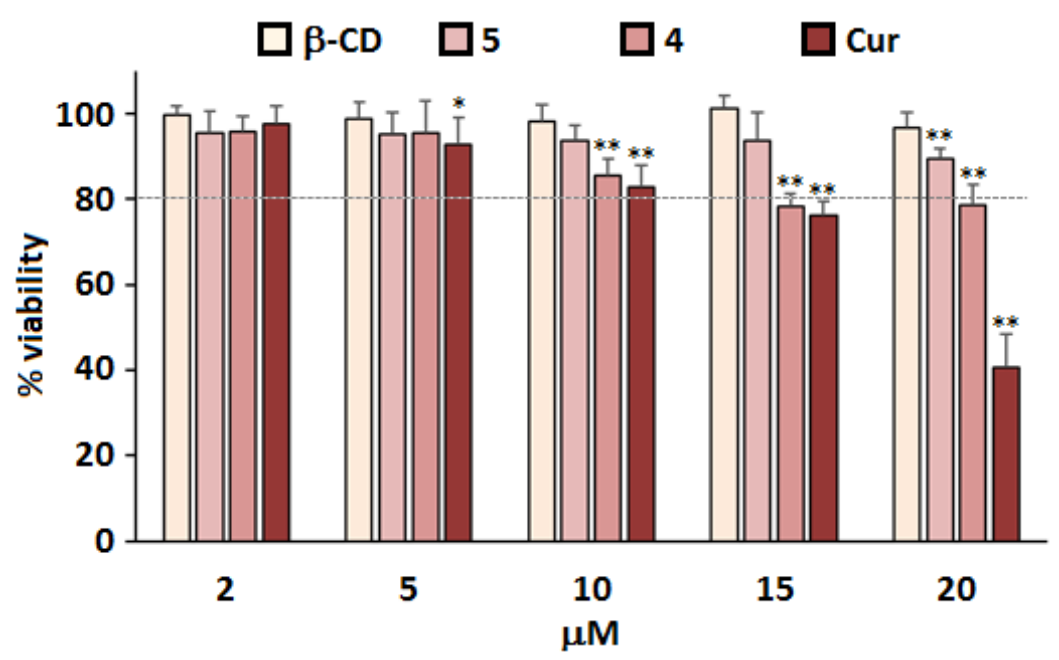

Figure 5. Cytotoxicity of $\beta-C D @ C u r 4$ and $(\beta-C D)_{2} @ C u r 5$ nanoconjugates. Primary cultures of rat embryo cortical neurons were isolated and prepared on Day 0 (D0) in vitro, followed by treatment on D3 with the indicated concentrations of Cur. MTT assay was performed after $24 \mathrm{~h}$ to assess cell viability. Results are shown as \% of viability of control cells treated with the same volume of DMSO alone; means and SD are shown for two separate cultures each with quadruplicate determinations. Statistical significance is shown as compared to values obtained from control cells $\left({ }^{*} p<0.05\right.$, ** $p<0.01)$.

In Figure 5, Cur showed a drug concentration-dependent cytotoxicity to rat cortical neurons cells. In fact, a significant decrease in cell viability was observed at Cur levels starting from $10 \mu \mathrm{M}$; only $48 \%$ of cells remained viable after treatments with $20 \mu \mathrm{M}$ Cur. Such results were probably due to the fact that Cur molecules were not well dispersed 
throughout the cell medium due to its lack of water solubility [24]. However, after clickcovalent binding of Cur with $\beta-C D$, no significant cytotoxicity to rat cortical neurons cells at corresponding Cur concentrations was observed. The degree of improved cell viability was also a function of $\beta-C D$ molecules number coupled with Cur viability ( $\beta$-CD@Cur $4<(\beta-C D)_{2} @ C$ ur 5$)$. These results were consistent with the photophysical properties of the studied molecules (Section 3.3), therefore suggesting that covalent binding of Cur to $\beta$-CD could promote its water solubility and reduce Cur toxicity in primary cultures of rat cortical neurons.

\section{Materials and Methods}

\subsection{Chemicals}

All chemicals were used without further purifications. $\beta$-cyclodextrin $(\beta-C D)$ and curcumin (Cur) were purchased from Sigma-Aldrich (Saint-Quentin Fallavier, France). All reactions involving Cur compounds were protected from the light by using aluminum foil around the reactors and other glassware. Deionized (DI) water was processed in a Milli-Q water purification system.

\subsection{Characterization}

The monitoring of the mono- and bi-propargylation of Cur was carried out using Macharey -Nagel ALUGRAM ${ }^{\circledR}$ SIL > G/UV254 thin-layer chromatography (TLC) plates and spots were visualized under ultraviolet (UV) light $(256 \mathrm{~nm}$ and $355 \mathrm{~nm})$. Cur-based products purifications were performed on Agilent 1100 high-performance liquid chromatography (HPLC) (Agilent, Santa Clara, CA, USA) using an Agilent Pursuit 5 C18 reverse phase column $(5 \mu \mathrm{m}, 150 \times 4.6 \mathrm{~mm})$ eluted with acetonitrile/water $\left(\mathrm{ACN} / \mathrm{H}_{2} \mathrm{O}\right.$, $v / v$ ) gradients from $10 / 90$ to $100 / 0$ in $25 \mathrm{~min}$, then $100 / 0$ for 10 min containing $0.1 \%$ trifluoroacetic acid (TFA). A flow rate of $1.0 \mathrm{~mL} / \mathrm{min}$ for analytical HPLC and of $12 \mathrm{~mL} / \mathrm{min}$ for preparative HPLC were used with UV detection at $254 \mathrm{~nm}$ and $420 \mathrm{~nm}$. A Brucker Advance $300 \mathrm{MHz}$ spectrophotometer was used to perform 1D and 2D NMR spectra (i.e., ${ }^{1} \mathrm{H},{ }^{13} \mathrm{C}, \mathrm{HSQC}$ and $\mathrm{HMBC}$ ). Deuterated DMSO with residual peaks at $\delta=2.5$ and $39.5 \mathrm{ppm}$ for ${ }^{1} \mathrm{H}$ and ${ }^{13} \mathrm{C}$ NMR, respectively, was chosen for NMR experiments at room temperature $(\mathrm{T}=298 \mathrm{~K}) . \delta$ and $J$ represented chemical shifts and coupling constants in parts per million (ppm) and hertz (Hz), respectively. Singlet (s), doublet (d), triplet (t), multiplet $(\mathrm{m})$, broad (br) or their combination defined the multiplicity. High-resolution mass spectroscopy with electrospray ionization method (ESI-HRMS) was performed using a Brucker MicrOTOF-Q HR spectrometer. Ultraviolet-Visible (UV-vis) absorption and fluorescence spectra were recorded on a Shimadzu UV-3600 double-beam UV-vis spectrophotometer and a Fluorolog-3 spectrofluorometer FL3-222, respectively.

\subsection{Synthesis of $\beta$-CD@Cur 4 and $(\beta-C D)_{2} @ C u r 5$ Nanoconjugates}

\subsubsection{Cur Mono-Alkyne 1 and Cur Di-Alkyne 2}

Compounds $\mathbf{1}$ and $\mathbf{2}$ were synthesized separately as described in the literature [22] with slight modifications by reacting Cur ( $200 \mathrm{mg}$, $0.543 \mathrm{mmol})$ in DMF ( $3 \mathrm{~mL}$ ) with $\mathrm{K}_{2} \mathrm{CO}_{3}$ and propargyl bromide (1.0 equiv. per propargylation) at room temperature under $\mathrm{N}_{2}$ for $48 \mathrm{~h}$. To avoid degradation of Cur, the reactions were performed in the dark. The progress of the reactions was monitored by TLC with EtOAc/hexane (50/50). After completion of the reactions, the solvent was removed under reduced pressure. The crude products were purified by preparative HPLC and the collected pure fractions were lyophilized over $24 \mathrm{~h}$ to yield $\mathbf{1}(45 \%)$ and $\mathbf{2}(70 \%)$ as orange powders. Compounds $\mathbf{1}$ and $\mathbf{2}$ were characterized by HPLC, ${ }^{1} \mathrm{H}$ NMR and HRMS (See supplementary data).

\subsection{2. $\beta$-CD@Cur 4 and $(\beta-C D)_{2} @ C u r 5$ Nanoconjugates}

Mono-6-azido- $\beta-C D 3$ was synthesized from $\beta$-CD in a two steps-process. The overall yield was $49 \%$. The protocol has been described recently by our team [23]. 
To a solution of Cur mono-alkyne 1 or Cur di-alkyne 2 (0.08 mmol, 1.0 equiv.) and 3 (1.0 equiv. per alkyne function) in $\mathrm{H}_{2} \mathrm{O} / \mathrm{DMF}(1 / 4, v / v, 5 \mathrm{~mL})$ was added successively $\mathrm{CuSO}_{4} \cdot 5 \mathrm{H}_{2} \mathrm{O}$ (0.1 equiv. per alkyne function) and $\mathrm{Na}$ ascorbate ( 0.5 equiv. per alkyne function). The reaction mixtures were maintained at room temperature under vigorous stirring in the dark for $24 \mathrm{~h}$. The solvent was evaporated under reduced pressure. Preparative HPLC was used to purify the crude product and the collected pure fractions were lyophilized over $24 \mathrm{~h}$ to afford $\beta$-CD@Cur $4(40 \%)$ and $(\beta-C D)_{2} @$ Cur $5(55 \%)$ as an orange powder and a yellowish powder, respectively.

$\beta$-CD@Cur 4: ${ }^{1} \mathrm{H}$ NMR (300 MHz, DMSO- $\left.d_{6}\right)$ : $\delta$ 2.85-4.45 (m, 54H, H2, H3, H4, H5, H6, $\mathrm{OH} 6, \mathrm{H} 7-\mathrm{OMe}$ and $\left.\mathrm{H}^{\prime}-\mathrm{OMe}\right), 4.48-5.26(\mathrm{~m}, 13 \mathrm{H}, \mathrm{H} 1, \mathrm{OH} 2, \mathrm{OH} 3, \mathrm{H} 1$ and H11), 5.26-6.08 $(3,12 \mathrm{H}, \mathrm{OH} 2$ and $\mathrm{OH} 3), 6.75\left(\mathrm{~d}, J=8.4 \mathrm{~Hz}, 1 \mathrm{H}, \mathrm{H}^{\prime}\right), 6.76\left(\mathrm{~d}, J=15.9 \mathrm{~Hz}, 1 \mathrm{H}, \mathrm{H}^{\prime}\right), 6.81(\mathrm{~d}$, $J=15.6 \mathrm{~Hz}, 1 \mathrm{H}, \mathrm{H} 3), 6.83(\mathrm{~d}, J=8.4 \mathrm{~Hz}, 1 \mathrm{H}, \mathrm{H} 9), 7.14(\mathrm{~d}, J=8.4 \mathrm{~Hz}, 1 \mathrm{H}, \mathrm{H} 10), 7.21$ (br s, $\left.1 \mathrm{H}, \mathrm{H}^{\prime}\right), 7.29\left(\mathrm{~d}, J=8.4 \mathrm{~Hz}, 1 \mathrm{H}, \mathrm{H} 10^{\prime}\right), 7.32(\mathrm{br} \mathrm{s}, 1 \mathrm{H}, \mathrm{H} 6), 7.56\left(\mathrm{~d}, J=15.9 \mathrm{~Hz}, 1 \mathrm{H}, \mathrm{H} 4^{\prime}\right)$, 7.58 (d, J = $15.6 \mathrm{~Hz}, 1 \mathrm{H}, \mathrm{H} 4), 8.19$ (s, 1H, H13), 9.68 (br s, 1H, H8'-OH). ${ }^{13} \mathrm{C} \mathrm{NMR}(75 \mathrm{MHz}$, DMSO- $d_{6}$ ): $\delta 50.4$ (C11), 55.6 (C7-OMe and C7'-OMe), 59.1 (C6), 59.9 (C6), 61.5 (C1), 70.0 (C2, C3 and $\mathrm{C} 5), 72.1$ (C2, C3 and $\mathrm{C} 5), 72.4$ (C2, C3 and $\mathrm{C} 5), 73.0$ (C2, C3 and $\mathrm{C} 5), 81.5$ (C4), 82.1 (C4), 83.4 (C4), 100.9 (C1), 101.9 (C1), $111.4(\mathrm{C} 6), 113.2\left(\mathrm{C}^{\prime}\right), 115.7$ (C9 and $\left.\mathrm{C}^{\prime}\right), 121.1$ (C3'), 12.3 (C3), $122.7\left(\mathrm{C} 10^{\prime}\right), 123.2$ (C10), 125.8 (C13), $126.3\left(\mathrm{C}^{\prime}\right), 128.0$ (C5), $140.1\left(\mathrm{C}^{\prime}\right)$, 141.0 (C4), 142.2 (C12), 148.0 (C8'), 149.2 (C7), 149.4 (C7'), 149.7 (C8), 182.7 (C2 and C2'). HRMS (ESI) for $\mathrm{C}_{66} \mathrm{H}_{91} \mathrm{~N}_{3} \mathrm{O}_{40}$ : [M + H] $]^{+}$calculated 1566.5257, found 1566.5531, [M + Na] $]^{+}$ calculated 1588.5076, found 1588.5293 and $[\mathrm{M}+2 \mathrm{H}]^{2+}$ calculated 783.7667, found 783.7844

$(\beta-C D)_{2} @$ Cur 5: ${ }^{1} \mathrm{H}$ NMR $\left(300 \mathrm{MHz}, \mathrm{DMSO}-d_{6}\right): \delta 3.04-3.75$ (m, 93H, H2, H3, H4, H5, $\mathrm{H} 6$ and $\mathrm{OH} 6), 3.78$ (s, 6H, H7-OMe), 3.95-4.07 (m, 3H, OH6), 4.47-5.62 (m, 48H, H1, OH2, $\mathrm{OH} 3, \mathrm{H} 1$ and H11), $7.00(\mathrm{~d}, J=15.3 \mathrm{~Hz}, 2 \mathrm{H}, \mathrm{H} 3), 7.20(\mathrm{~d}, J=8.4 \mathrm{~Hz}, 2 \mathrm{H}, \mathrm{H} 9), 7.31(\mathrm{~d}, J=8.4$ $\mathrm{Hz}, 2 \mathrm{H}, \mathrm{H} 10), 7.37$ (s, 2H, H6), 7.61 (d, J = $15.3 \mathrm{~Hz}, 2 \mathrm{H}, \mathrm{H} 4), 8.17$ (s, 2H, H13). ${ }^{13} \mathrm{C}$ NMR (75 MHz, DMSO- $d_{6}$ ): $\delta 50.4$ (C11), 55.7 (C7-OMe), 59.0 (C6), 59.9 (C6), 61.5 (C1), 70.0 (C2, $\mathrm{C} 3$ and $\mathrm{C} 5), 71.7$ (C2, $\mathrm{C} 3$ and $\mathrm{C} 5), 72.1$ (C2, $\mathrm{C} 3$ and $\mathrm{C} 5), 72.4$ (C2, $\mathrm{C} 3$ and $\mathrm{C} 5), 73.0$ (C2, C3 and C5), 81.1 (C4), 81.5 (C4), 82.1 (C4), 83.4 (C4), 101.3 (C1), 102.0 (C1), 111.3 (C6), 112.9 (C9), 118.8 (C3), 124.1 (C10), 125.8 (C13), 127.0 (C5), 142.0 (C12), 144.7 (C4), 149.1 (C8), 150.5 (C7), 193.1 (C2). HRMS (ESI) for $\mathrm{C}_{111} \mathrm{H}_{162} \mathrm{~N}_{6} \mathrm{O}_{74}$ : $[\mathrm{M}+2 \mathrm{H}]^{2+}$ calculated 1382.4627, found 1382.5022, $[\mathrm{M}+2 \mathrm{Na}]^{2+}$ calculated 1404.4446, found 1404.4793 and $[\mathrm{M}+2 \mathrm{~K}]^{2+}$ calculated 1420.4186, found 1420.4437 .

\subsection{Nanoconjugates Size and $\zeta$-Potential Measurements}

The size, polydispersity index (PDI) and $\zeta$-potential of the synthesized nanoconjugates were measured following their dilution with ultrapure water (1:200) using DLS (Zetasizer Nano ZS, Malvern, UK). Nanoconjugates were examined by standard capillary electrophoresis cell. The size and $\zeta$-potential were measured at room temperature $\left(25^{\circ} \mathrm{C}\right)$ using a 0.01 absorbance under a scattering angle and a refractive index of $173^{\circ}$ and 1.59 , respectively.

\subsection{Nanoconjugates Morphological Study}

The morphology of the synthesized nanoconjugates in water was monitored via TEM using a negative staining method. In brief, the nanoconjugates were first diluted in distilled water. A $2 \%$ ammonium molybdate solution was added with a ratio of 1:1. The mixtures were reserved at room temperature for $3 \mathrm{~min}$. Then, one drop of the nanoconjugates suspension was deposited and dried on a grid type EMS CF200-Cu Formvar carbon-coated copper grid (200 mesh, $3 \mathrm{~mm}$ diameter HF 36). The nanoconjugates morphology was studied with a Philips CM20 TEM equipped with an Olympus TEM CCD camera at $200 \mathrm{kV}$.

\section{6. $\beta$-CD Effect on Cur Disaggregation in Aqueous Medium}

The influence of the presence of $\beta$-CD on the solubility of Cur in $\beta$-CD@Cur 4 and ( $\beta$ $\mathrm{CD})_{2} @$ Cur 5 nanoconjugates in water at room temperature was studied by comparing their UV-vis absorption, fluorescence emission and fluorescence lifetime spectra with those of 
free Cur in the same conditions. Briefly, each product was dissolved in $\mathrm{D}_{2} \mathrm{O}$. Fluorescence $\left(\Phi_{\mathrm{f}}\right)$ quantum yield was determined using Quinine (Quin) solution in acetonitrile as fluorescence standard $\left(\Phi_{\mathrm{f}}=0.55\right)$ [33].

\subsection{Cell Cytotoxicity Studies}

\subsubsection{Primary Culture of Cortical Neurons}

Cell culture studies were carried out at the Bioavailability-Bioactivity (Bio-DA, Lorraine, France) platform. Primary cultures of cortical neurons were prepared from rat fetuses (day 16-17 of gestation) as previously reported [31,32]. Cells were plated at $10 \times 10^{4}$ cells $/ \mathrm{cm}^{2}$ onto plates and cultured in neuronal culture medium M2 [DMEMF12 (Invitrogen, Illkirch, France) medium containing $0.5 \mu \mathrm{M}$ insulin, $60 \mu \mathrm{M}$ putrescine, $30 \mathrm{nM}$ sodium selenite, $100 \mu \mathrm{M}$ transferrin, $10 \mathrm{nM}$ progesterone and $0.1 \%(w / v)$ ovalbumin (Sigma-Aldrich (Saint-Quentin Fallavier, France)]. Neurons were incubated at $35^{\circ} \mathrm{C}$ in $6 \%$ $\mathrm{CO}_{2}$ with day (D) 0 being the day of the preparation of the cells. $\beta-\mathrm{CD}$, Cur, $\beta$-CD@Cur 4 and $(\beta-C D)_{2} @$ Cur 5 were first dissolved in DMSO (Final volume of DMSO $\leq 0.25 \%$ ), and the solutions were diluted to the desired concentrations in M2 culture medium. On Day 3, the neuronal culture medium was treated with each compound separately at a final Cur concentration of $2-20 \mu \mathrm{M}$ and incubated for $24 \mathrm{~h}$ at $35^{\circ} \mathrm{C}$ in $6 \% \mathrm{CO}_{2}$. Control cells were treated with the same concentrations of DMSO alone that are not toxic for cells.

\subsubsection{MTT Test}

The neuronal viability of the different molecules was assessed using the 3-(4,5 dimethylthiazol-2-yl)-2,5-diphenyltetrazolium bromide (MTT, Sigma-Aldrich (Saint-Quentin Fallavier, France) $)$ reduction activity assay. MTT solution $\left(4 \mathrm{mg} / \mathrm{mL}, 37^{\circ} \mathrm{C}\right)$ was added to each well and the plates were then incubated for $1 \mathrm{~h}$ at $35^{\circ} \mathrm{C}$ in $6 \% \mathrm{CO}_{2}$. Media was removed and replaced with DMSO followed by incubation while shaking at room temperature for $10 \mathrm{~min}$. The absorbance of formazan was measured at wavelength of $570 \mathrm{~nm}$ [(Fluostar Galaxy, Biolise software) (BMG Lab technologies, Offenberg, Germany)]. Cell viability was expressed as percentage of living cells compared to values obtained from control untreated cells.

\subsubsection{Statistical Analysis}

Experiments were performed in triplicate, and results are shown as the mean $\pm \mathrm{SD}$, unless otherwise indicated. A variance analysis was done by ANOVA supplemented with a Scheffe's post hoc test and a $p$-value greater than 0.05 was regarded as significant.

\section{Conclusions}

Two novel nanoconjugates denoted $\beta$-CD@Cur and $(\beta-C D)_{2} @$ Cur self-assembled in water to form nanoparticles with an average diameter size of around 35 and $120 \mathrm{~nm}$, respectively. These nanoconjugates were successfully synthesized using CuAAC click chemistry strategy via a triazole covalent link between Cur and $\beta-C D$ molecules. The chemical structure and purity of the synthesized nanoconjugates was checked by NMR spectroscopy $\left({ }^{1} \mathrm{H},{ }^{13} \mathrm{C}, \mathrm{HSQC}\right.$ and HMBC), ESI-HRMS and HPLC analyses. Furthermore, the $\beta$-CD effect on the disaggregation of Cur in aqueous medium and cell cytotoxicity effect on rat cortical neurons were investigated.

The findings indicated that $\beta$-CD covalent binding with Cur led to an improvement of its solubility and photophysical properties in aqueous conditions preventing cytotoxic effects. Firstly, UV-vis absorption and fluorescence emission spectra in $\mathrm{D}_{2} \mathrm{O}$ revealed that, compared to free Cur, water solubility of the nanoconjugates increased with the number of $\beta-C D$ resulting in an improvement of the absorption intensity and in the restoration of fluorescence. Secondly, the addition of $\beta$-CD reduced significantly the toxicity of Cur illustrated by around $90 \%$ and $80 \%$ rat cortical neurons viability for $(\beta$ $\mathrm{CD})_{2} @$ Cur and $\beta-\mathrm{CD} @ \mathrm{Cur}$ nanoconjugate, respectively, at $20 \mu \mathrm{M}$ concentration, compared to only $48 \%$ viability with free Cur at the same concentration. These results showed the 
potential interest of these nanoconjugates as possible new Cur derivatives for application in neurodegenerative diseases prevention. The next step will be to determine the efficacy of curcumin's neuroprotective effects of these two nanoconjugates, including protection against $A \beta$ cell toxicity, and antioxidative properties using cell and animal models, with the goal towards developing prevention strategies to reduce risk of neurodegenerative diseases.

Supplementary Materials: The following are available online at https: / www.mdpi.com/1422-0 067/22/6/3255/s1, Figure S1: ${ }^{1} \mathrm{H}$ NMR spectrum (300 MHz, DMSO- $d_{6}, 298 \mathrm{~K}$ ) of $\beta$-CD@Cur 4 nanoconjugate, Figure S2: $J$ mod ${ }^{13} \mathrm{C}$ NMR spectrum $\left(75 \mathrm{MHz}, \mathrm{DMSO}-d_{6}, 298 \mathrm{~K}\right)$ of $\beta$-CD@Cur 4 nanoconjugate, Figure S3: 2D HSQC NMR spectrum (300 MHz, DMSO- $d_{6}, 298 \mathrm{~K}$ ) of $\beta$-CD@Cur 4 nanoconjugate, Figure S4: 2D HMBC NMR spectrum (300 MHz, DMSO- $d_{6}, 298 \mathrm{~K}$ ) of $\beta$-CD@Cur 4 nanoconjugate, Figure S5: ${ }^{1} \mathrm{H}$ NMR spectrum (300 MHz, DMSO- $\left.d_{6}, 298 \mathrm{~K}\right)$ of $(\beta-\mathrm{CD})_{2} @ \mathrm{Cur} 5$ nanoconjugate, Figure S6: $J$ mod ${ }^{13} \mathrm{C}$ NMR spectrum $\left(75 \mathrm{MHz}, \mathrm{DMSO}-d_{6}, 298 \mathrm{~K}\right)$ of $(\beta-\mathrm{CD})_{2} @ \mathrm{Cur} 5$ nanoconjugate, Figure S7: 2D HSQC NMR spectrum (300 MHz, DMSO- $\left.d_{6}, 298 \mathrm{~K}\right)$ of $(\beta-C D)_{2} @ C u r 5$ nanoconjugate, Figure S8: 2D HMBC NMR spectrum (300 MHz, DMSO- $\left.d_{6}, 298 \mathrm{~K}\right)$ of $(\beta-\mathrm{CD})_{2} @ \mathrm{Cur} 5$ nanoconjugate.

Author Contributions: Conceptualization, A.B.M., S.A. and E.A.-T.; methodology, A.B.M., S.A., C.M. and E.A.-T.; software, A.B.M.; validation, A.B.M., S.A., C.F., C.M., F.T.Y. and E.A.-T.; formal analysis, A.B.M., S.A., C.M. and E.A.-T.; investigation, A.B.M.; resources, A.B.M., S.A., F.T.Y. and E.A.-T.; data curation, A.B.M., S.A. and F.T.Y.; writing-original draft preparation, A.B.M. and S.A.; writingreview and editing, A.B.M., S.A., C.F., F.T.Y. and E.A.-T.; visualization, A.B.M.; supervision, S.A., C.F., C.M. and E.A.-T.; project administration, S.A., C.F., C.M., F.T.Y. and E.A.-T.; funding acquisition, A.B.M., S.A., C.F., C.M., F.T.Y. and E.A.-T. All authors have read and agreed to the published version of the manuscript.

Funding: This research was funded by "Impact Biomolecules" project of the "Lorraine Université $\mathrm{d}^{\prime}$ Excellence" (in the context of the «Investissements d'avenir» program implemented by the French National Research Agency (ANR)).

Institutional Review Board Statement: The animals were housed in government-certified animal facilities in accordance with the European Communities Council Directive (EU 2010/63) for the use and care of laboratory animals. Since the procedure for preparation of rat embryo cortical neurons involved tissue sampling after animal sacrifice using authorized methodology (overdose of isoflurane gas anesthesia), ethical review and approval were waived for this study (directive 2013-118).

Informed Consent Statement: Not applicable.

Data Availability Statement: Data is contained within the article or supplementary material.

Acknowledgments: The authors gratefully acknowledge Olivier Fabre for running NMR experiments, Solenne Fleutot and Thomas Girardet for TEM experiments and, Marion Huguet and Claire Soligot for isolation of Rat Embryonic Neural Cells.

Conflicts of Interest: The authors declare no competing financial interest.

$\begin{array}{ll}\text { Abbreviations } \\ \text { Cur } & \text { Curcumin } \\ \beta-C D & \beta \text {-Cyclodextrin } \\ \text { CuAAC } & \text { Copper-catalyzed azide-alkyne cycloaddition } \\ \text { BBB } & \text { Blood Brain Barrier } \\ \text { AD } & \text { Alzheimer's disease }\end{array}$

\section{References}

1. Erkkinen, M.G.; Kim, M.-O.; Geschwind, M.D. Clinical Neurology and Epidemiology of the Major Neurodegenerative Diseases. Cold Spring Harb. Perspect. Biol. 2018, 10, a033118. [CrossRef]

2. Bertram, L.; Tanzi, R.E. The genetic epidemiology of neurodegenerative disease. J. Clin. Investig. 2005, 115, 1449-1457. [CrossRef] 
3. Torres-Ramos, Y.; Montoya-Estrada, A.; Cisneros, B.; Tercero-Pérez, K.; León-Reyes, G.; Leyva-García, N.; Hernández-Hernández, O.; Magaña, J.J. Oxidative Stress in Spinocerebellar Ataxia Type 7 Is Associated with Disease Severity. Cerebellum 2018, 17, 601-609. [CrossRef] [PubMed]

4. Grabrucker, A.M.; Ruozi, B.; Belletti, D.; Pederzoli, F.; Forni, F.; Vandelli, M.A.; Tosi, G. Nanoparticle transport across the blood brain barrier. Tissue Barriers 2016, 4, e1153568. [CrossRef] [PubMed]

5. Voulgaropoulou, S.D.; Van Amelsvoort, T.; Prickaerts, J.; Vingerhoets, C. The effect of curcumin on cognition in Alzheimer's disease and healthy aging: A systematic review of pre-clinical and clinical studies. Brain Res. 2019, 1725, 146476. [CrossRef] [PubMed]

6. Mathew, A.; Fukuda, T.; Nagaoka, Y.; Hasumura, T.; Morimoto, H.; Yoshida, Y.; Maekawa, T.; Venugopal, K.; Kumar, D.S. Curcumin Loaded-PLGA Nanoparticles Conjugated with Tet-1 Peptide for Potential Use in Alzheimer's Disease. PLoS ONE 2012, 7, e32616. [CrossRef]

7. Giacomeli, R.; Izoton, J.C.; dos Santos, R.B.; Boeira, S.P.; Jesse, C.R.; Haas, S.E. Neuroprotective effects of curcumin lipid-core nanocapsules in a model Alzheimer's disease induced by $\beta$-amyloid 1-42 peptide in aged female mice. Brain Res. 2019, 1721, 146325. [CrossRef]

8. Maiti, P.; Dunbar, G.L. Use of Curcumin, a Natural Polyphenol for Targeting Molecular Pathways in Treating Age-Related Neurodegenerative Diseases. Int. J. Mol. Sci. 2018, 19, 1637. [CrossRef] [PubMed]

9. Jampílek, J.; Král'ová, K.; Novák, P.; Novák, M. Nanobiotechnology in Neurodegenerative Diseases; Rai, M., Yadav, A., Eds.; Springer Nature: Cham, Switzerland, 2019; Volume 4, pp. 65-138. [CrossRef]

10. Del Prado-Audelo, M.L.; Caballero-Florán, I.H.; Meza-Toledo, J.A.; Mendoza-Muñoz, N.; González-Torres, M.; Florán, B.; Cortés, H.; Leyva-Gómez, G. Formulations of Curcumin Nanoparticles for Brain Diseases. Biomolecules 2019, 9, 56. [CrossRef]

11. Sun, M.; Su, X.; Ding, B.; He, X.; Liu, X.; Yu, A.; Lou, H.; Zhai, G. Advances in nanotechnology-based delivery systems for curcumin. Nanomedicine 2012, 7, 1085-1100. [CrossRef]

12. Del Prado-Audelo, M.; Magaña, J.; Mejía-Contreras, B.; Borbolla-Jiménez, F.; Giraldo-Gomez, D.; Piña-Barba, M.; QuintanarGuerrero, D.; Leyva-Gómez, G. In vitro cell uptake evaluation of curcumin-loaded PCL/F68 nanoparticles for potential application in neuronal diseases. J. Drug Deliv. Sci. Technol. 2019, 52, 905-914. [CrossRef]

13. Camilleri, P.; Haskins, N.J.; Hewlett, D.R. $\beta$-Cyclodextrin interacts with the Alzheimer amyloid $\beta$-A4 peptide. FEBS Lett. 1994, 341, 256-258. [CrossRef]

14. Yao, J.; Ho, D.; Calingasan, N.Y.; Pipalia, N.H.; Lin, M.T.; Beal, M.F. Neuroprotection by cyclodextrin in cell and mouse models of Alzheimer disease. J. Exp. Med. 2012, 209, 2501-2513. [CrossRef] [PubMed]

15. Dandawate, P.R.; Vyas, A.; Ahmad, A.; Banerjee, S.; Deshpande, J.; Swamy, K.V.; Jamadar, A.; Dumhe-Klaire, A.C.; Padhye, S.; Sarkar, F.H. Inclusion Complex of Novel Curcumin Analogue CDF and $\beta$-Cyclodextrin (1:2) and Its Enhanced In Vivo Anticancer Activity Against Pancreatic Cancer. Pharm. Res. 2012, 29, 1775-1786. [CrossRef]

16. Tomren, M.; Masson, M.; Loftsson, T.; Tønnesen, H.H. Studies on curcumin and curcuminoids: XXXI. Symmetric and asymmetric curcuminoids: Stability, activity and complexation with cyclodextrin. Int. J. Pharm. 2007, 338, 27-34. [CrossRef]

17. Yallapu, M.M.; Jaggi, M.; Chauhan, S.C. $\beta$-Cyclodextrin-curcumin self-assembly enhances curcumin delivery in prostate cancer cells. Colloids Surf. B Biointerfaces 2010, 79, 113-125. [CrossRef]

18. Hegge, A.B.; Vukicevic, M.; Bruzell, E.; Kristensen, S.; Tønnesen, H. Solid dispersions for preparation of phototoxic supersaturated solutions for antimicrobial photodynamic therapy (aPDT): Studies on curcumin and curcuminoides L. Eur. J. Pharm. Biopharm. 2013, 83, 95-105. [CrossRef] [PubMed]

19. Quitschke, W.W.; Steinhauff, N.; Rooney, J. The effect of cyclodextrin-solubilized curcuminoids on amyloid plaques in Alzheimer transgenic mice: Brain uptake and metabolism after intravenous and subcutaneous injection. Alzheimer's Res. Ther. 2013 , 5, 16. [CrossRef]

20. Cheng, K.K.; Yeung, C.F.; Ho, S.W.; Chow, S.F.; Chow, A.H.L.; Baum, L. Highly Stabilized Curcumin Nanoparticles Tested in an In Vitro Blood-Brain Barrier Model and in Alzheimer's Disease Tg2576 Mice. AAPS J. 2012, 15, 324-336. [CrossRef]

21. Ramdani, L.; Bourboulou, R.; Belkouch, M.; Jebors, S.; Tauran, Y.; Parizot, C.; Suwinska, K.; Coleman, A.W.; Duyckaerts, C.; Lazar, A.N. Multifunctional Curcumin-Nanocarriers Based on Host-Guest Interactions for Alzheimer Disease Diagnostic. J. Nanomed. Nanotechnol. 2015, 6, 2. [CrossRef]

22. Raja, K.; Alonso, A.; Banerjee, P.; Dolai, S.; Corbo, C.; Averick, S.; Mogha, A.; Debnath, S. Curcumin Derivatives. WO 2011106691A2. 2011. Available online: https://patentimages.storage.googleapis.com/44/6a/79/e7561b802ebbd8/WO20111 06691A2.pdf (accessed on 23 March 2021).

23. Ben Mihoub, A.; Youssef, Z.; Colombeau, L.; Juan-Hureaux, V.; Arnoux, P.; Frochot, C.; Vanderesse, R.; Acherar, S. Inclusion complex vs. conjugation of hydrophobic photosensitizers with $\beta$-cyclodextrin: Improved disaggregation and photodynamic therapy efficacy against glioblastoma cells. Mater. Sci. Eng. C 2020, 109, 110604. [CrossRef]

24. Sun, T.; Zhang, H.; Kong, L.; Qiao, H.; Li, Y.; Xin, F.; Hao, A. Controlled transformation from nanorods to vesicles induced by cyclomaltoheptaoses ( $\beta$-cyclodextrins). Carbohydr. Res. 2011, 346, 285-293. [CrossRef]

25. Provder, T. Challenges in particle size distribution measurement past, present and for the 21st century. Prog. Org. Coatings 1997, 32, 143-153. [CrossRef]

26. Hamaguchi, T.; Ono, K.; Yamada, M. REVIEW: Curcumin and Alzheimer's Disease. CNS Neurosci. Ther. 2010, 16, 285-297. [CrossRef] 
27. Kee, T.W.; Adhikary, R.; Carlson, P.J.; Mukherjee, P.; Petrich, J.W. Femtosecond Fluorescence Upconversion Investigations on the Excited-State Photophysics of Curcumin. Aust. J. Chem. 2011, 64, 23-30. [CrossRef]

28. Mandal, S.; Banerjee, C.; Ghosh, S.; Kuchlyan, J.; Sarkar, N. Modulation of the Photophysical Properties of Curcumin in Nonionic Surfactant (Tween-20) Forming Micelles and Niosomes: A Comparative Study of Different Microenvironments. J. Phys. Chem. B 2013, 117, 6957-6968. [CrossRef]

29. Gonçalves, J.L.; Valandro, S.R.; Poli, A.L.; Schmitt, C.C. Influence of clay minerals on curcumin properties: Stability and singlet oxygen generation. J. Mol. Struct. 2017, 1143, 1-7. [CrossRef]

30. Baglole, K.N.; Boland, P.G.; Wagner, B.D. Fluorescence enhancement of curcumin upon inclusion into parent and modified cyclodextrins. J. Photochem. Photobiol. A Chem. 2005, 173, 230-237. [CrossRef]

31. Malaplate, C.; Poerio, A.; Huguet, M.; Soligot, C.; Passeri, E.; Kahn, C.J.F.; Linder, M.; Arab-Tehrany, E.; Yen, F.T. Neurotrophic Effect of Fish-Lecithin Based Nanoliposomes on Cortical Neurons. Mar. Drugs 2019, 17, 406. [CrossRef]

32. Colin, J.; Allouche, A.; Chauveau, F.; Corbier, C.; Pauron-Gregory, L.; Lanhers, M.-C.; Claudepierre, T.; Yen, F.T.; Oster, T.; Malaplate-Armand, C. Improved Neuroprotection Provided by Drug Combination in Neurons Exposed to Cell-Derived Soluble Amyloid- $\beta$ Peptide. J. Alzheimer's Dis. 2016, 52, 975-987. [CrossRef]

33. Brouwer, A.M. Standards for photoluminescence quantum yield measurements in solution (IUPAC Technical Report). Pure Appl. Chem. 2011, 83, 2213-2228. [CrossRef] 